Jessica Schiller*, Dagmar Lackschewitz, Christian Buschbaum, Karsten Reise, Shaojun Pang and Kai Bischof

\title{
Heading northward to Scandinavia: Undaria pinnatifida in the northern Wadden Sea
}

https://doi.org/10.1515/bot-2017-0128

Received 21 December, 2017; accepted 19 June, 2018; online first 11 July, 2018

\begin{abstract}
The kelp Undaria pinnatifida, native to East Asian shores, was unintentionally introduced with Pacific oysters into the Mediterranean in 1971. Intentional introduction from there to the French Atlantic coast 12 years later led to a gradual spread to the British Isles and the North Sea. Here, we report on the northernmost established population in continental Europe, and suggest a further spread into Scandinavian waters to be almost inevitable. In 2016, several thalli were found washed ashore at the eastern side of the island of Sylt in the northern Wadden Sea (German Bight, Eastern North Sea). Most specimens bore fertile sporophylls and thallus lengths of $>1 \mathrm{~m}$ were common. In June 2017, 91 sporophytes were found attached to a mixed bed of Pacific oysters and native blue mussels, located just below low tide level in a moderately sheltered position. Mean thallus length was $0.2 \mathrm{~m}$ and the longest $0.7 \mathrm{~m}$. Most had distinctive sporophylls and released spores in the laboratory. From sporophylls collected in the previous year, we successfully reared a new generation, demonstrating the kelp's potential for further spread by natural means or human vectors.
\end{abstract}

Keywords: introduced non-native species; neobiota; Pacific oysters; range expansion; Undaria pinnatifida.

\section{Introduction}

The brown macroalga Undaria pinnatifida is native to South Korea, parts of Japan and China's Zhoushan

\footnotetext{
*Corresponding author: Jessica Schiller, Bremen Marine Ecology (BreMarE), Marine Botany, University of Bremen, Leobener Str. 3, 28359 Bremen, Germany, e-mail: j.schiller@uni-bremen.de Dagmar Lackschewitz, Christian Buschbaum and Karsten Reise: Alfred Wegener Institute, Helmholtz Centre for Polar and Marine Research, Wadden Sea Station Sylt, Hafenstr. 43, 25992 List, Germany Shaojun Pang: Institute of Oceanology, Chinese Academy of Sciences, Qingdao 266071, P.R. China

Kai Bischof: Bremen Marine Ecology (BreMarE), Marine Botany, University of Bremen, Leobener Str. 3, 28359 Bremen, Germany
}

archipelago (Hay and Villouta 1993, Morelissen et al.2013). It originally inhabits the lower intertidal and subtidal zones of rocky shores (Hay and Villouta 1993, Morelissen et al. 2013), but can also be found growing on virtually any natural and artificial hard substratum (Floc'h et al. 1991, Wotton et al. 2004). This kelp species has been a well-known food source in Asia and has recently gained increasing attention as an introduced species in many coastal areas worldwide (Hay and Luckens 1987, Nisizawa et al. 1987, Yamanaka and Akiyama 1993, Lowe et al. 2000). The first accidental introduction of $U$. pinnatifida to Europe occurred in 1971 in the Thau lagoon (French Mediterranean). Its introduction is thought to be associated with movement of Pacific oysters [Magallana (Crassostrea) gigas] brought from Japan for farming (Floc'h et al. 1991). In 1983, specimens were brought for cultivation experiments from the Mediterranean to Brittany (France), the first free living specimens were later detected in 1987 (Figure 1A; Minchin and Nunn 2014). These were most likely facilitated by anthropogenic vectors, and $U$. pinnatifida continued to spread along European coasts, first observed in southern England in 1994 and on the shores of Belgium and the Netherlands in 1999. Until now, the most northern occurrence of $U$. pinnatifida was in Belfast Lough (Northern Ireland) in 2015 and on the Dutch island of Terschelling in continental Europe in 2009 (Figure 1B, Gittenberger et al. 2015, Minchin et al. 2017).

In addition to dispersal by aquaculture activities and shipping, overland transport of Undaria pinnatifida with fishing gear has been reported (Bollen et al. 2017). Its highly plastic physiology and morphology allow U. pinnatifida to adapt well to many new environments, which may explain its success as a worldwide invader (Dean and Hurd 2007). Previous studies suggested that natural dispersal mechanisms, namely spore production and release, as well as severed floating thalli or sporophylls, result in only a limited range expansion of around $100 \mathrm{~m}$ per generation (Forrest et al. 2000). Still, the number of offspring potentially produced by individual sporophytes is high. Millions of zoospores are released from each sporophyll and, therefore, populations may grow very rapidly (Shan et al. 2016). The impact of $U$. pinnatifida on native communities may differ depending on the coastal system 


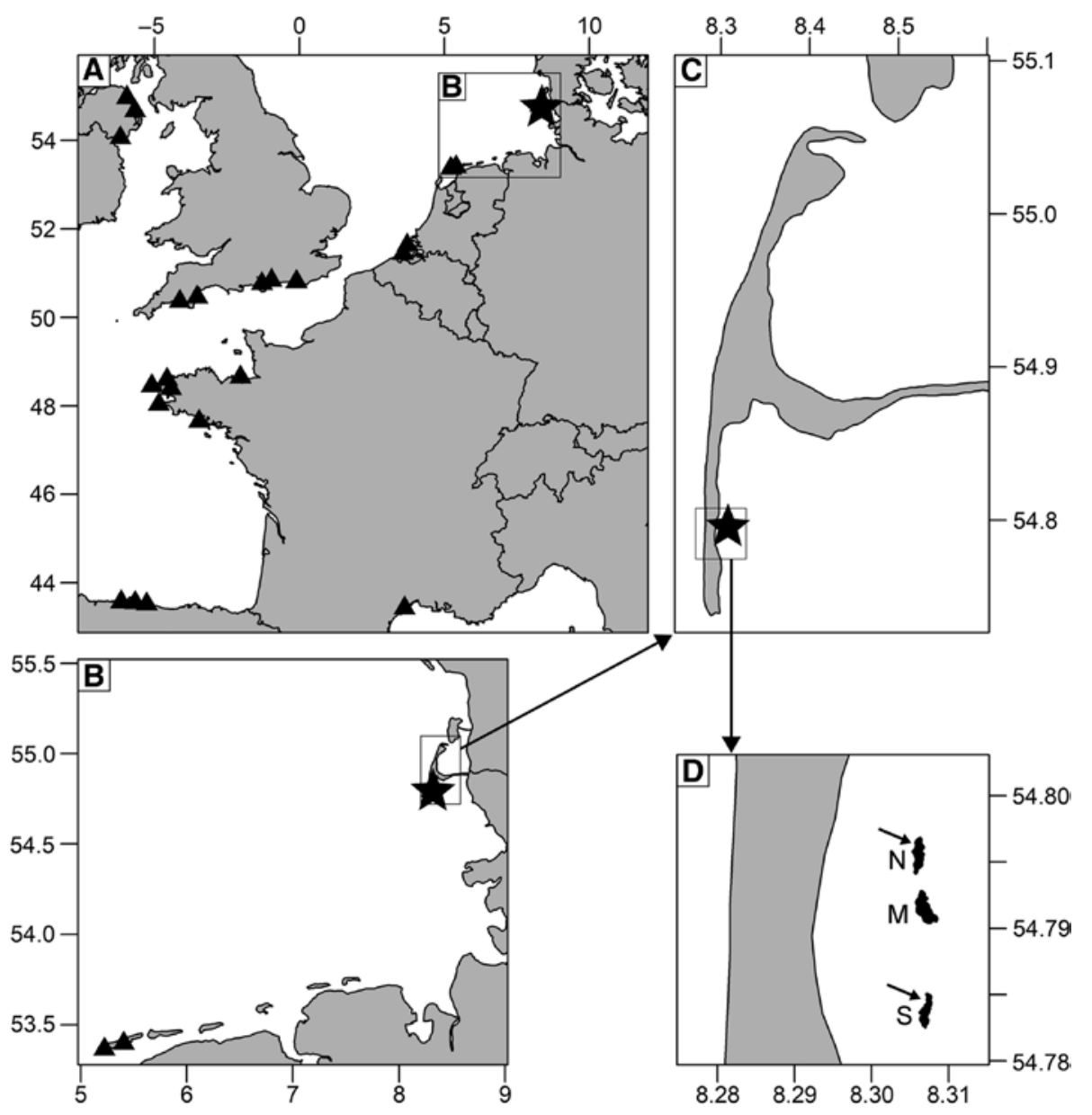

Figure 1: Distribution of Undaria pinnatifida populations previously reported (triangles) and the newly established one on Sylt (stars). (A) Examples of populations in Europe (Minchin and Nunn 2014, Gittenberger et al. 2015). (B) Easternmost documented European population in 2014 (Gittenberger et al. 2015) and 2017. (C) Island of Sylt with box marking the major U. pinnatifida wash-up zone and location of the attached $U$. pinnatifida on the sampled oyster reef $\left(54^{\circ} 47^{\prime} 44.4^{\prime \prime} \mathrm{N} 8^{\circ} 18^{\prime} 24.7^{\prime \prime} \mathrm{E}\right)$. (D) Oyster reefs (north, middle, south) off the eastern shore of Sylt with arrows marking the growth sites. Numbers on axes are longitude and latitude in degrees $\mathrm{N}$ and $\mathrm{E}$.

investigated. Native species richness may be reduced but, in some circumstances, the alga could have a positive effect where it provides an extra substratum for native species to grow (e.g. Casas et al. 2004; Irigoyen et al. 2011).

Here we report the first detection of Undaria pinnatifida in the northern Wadden Sea (southeastern North Sea) and provide a baseline for further research on the population development of this non-native kelp and its potential effects on native communities in the Wadden Sea ecosystem.

\section{Materials and methods}

Individuals of Undaria pinnatifida (Harvey) Suringar were first found washed ashore on intertidal sandflats on the eastern side of the island of Sylt in the northern Wadden Sea in August 2016 during a routine non-native species monitoring survey (for detailed information on the monitoring program see Buschbaum et al. 2012). On several occasions between August 2016 and June 2017, a total of more than 100 sporophytes were found washed ashore (hereafter "floating sporophytes") between Rantum and Hörnum in southern Sylt (Figure 1C).

No specimens of Undaria pinnatifida were observed during dredge sampling of mussel reefs in the area east of the wash-up zone in March 2017. In June 2017, three oyster reefs, located in the shallow subtidal near the wash-up zone were investigated during low tide (Figure 1D). Contours and profiles of the reefs were recorded using a GPSbased application (MapMyWalk® 2017, Under Armour $^{\circledR}$ Inc., Baltimore, MD, USA) and all U. pinnatifida sporophytes found attached to the oyster reefs were collected. 
The substratum as well as major components of the associated flora and fauna were identified. Undaria pinnatifida sporophytes were transported to the laboratory (Alfred Wegener Institute, Helmholtz Centre for Polar and Marine Research, Wadden Sea Station Sylt, Germany), where all individuals were photographed, the presence of sporophylls was recorded and thallus lengths and midrib widths were measured. For damaged thalli, the full length without damage was estimated based on the midrib width and length. Previous studies (Castric-Fey et al. 1999) and our own experience showed that the midrib width can serve as a proxy for full sporophyte size (Schiller et al. unpublished). However, as morphology and size ratios of $U$. pinnatifida vary with growth site and conditions (Castric-Fey et al. 1999, Skriptsova et al. 2004), the midrib width in this study only serves as an independent measurement for sporophyte size distribution.

Floating sporophytes were measured in the field or digitally from photos using Image J (Schneider et al. 2012).

To test for zoospore release in vitro, 27 of the attached mature sporophytes were haphazardly selected and a method adapted from Shan and Pang (2009) was used. Sporophylls were cut from the plants, cleaned of epiphytes and dried in closed petri dishes for approximately $24 \mathrm{~h}$ at $12^{\circ} \mathrm{C}$ without light. Pieces of each sporophyll were immersed in petri dishes filled with fresh seawater at room temperature and natural light. They were observed under the microscope after 24 and $48 \mathrm{~h}$.

For germination experiments, a washed up specimen collected in October 2016 was used to release viable spores in the laboratory (Marine Botany, BreMarE, University of Bremen, Germany). Pieces of the sporophyll were cleaned thoroughly as described in Redmond et al. (2014) and desiccated in petri dishes for $24 \mathrm{~h}$ at $12^{\circ} \mathrm{C}$, before being immersed in Provasoli enriched sterilized natural seawater (PES). After 24-48 h at 20-30 $\mu \mathrm{mol}$ photons $\mathrm{m}^{-2} \mathrm{~s}^{-1}, 12: 12 \mathrm{~h}$ $\mathrm{L}: \mathrm{D}$ and $18^{\circ} \mathrm{C}$, spores germinated into gametophytes. In several subsequent experiments, sporophytes were successfully obtained from this culture by adapting the method of Shan et al. (2013). Gametophyte filaments were broken up into fragments and irradiance reduced to $5 \mu \mathrm{mol}$ photons $\mathrm{m}^{-2} \mathrm{~s}^{-1}$ for $24 \mathrm{~h}$, then increased to $50 \mu \mathrm{mol}$ photons $\mathrm{m}^{-2} \mathrm{~s}^{-1}$ with medium changes every 3 days.

Statistical analysis was performed in R using a generalized linear model with Gaussian dispersion parameters and $\mathrm{p}<0.05$ (R Core Team 2015).

\section{Results and discussion}

Sea surface temperature in late June ranged between 16 and $17^{\circ} \mathrm{C}$ (own measurements). However, intense irradiance and air temperatures can increase the temperature range significantly. In total, we found 91 attached specimens of Undaria pinnatifida (Figure 2), which were detected only on the western fringe of the northern oyster reefs, except for a single strongly damaged individual on the southern reef.

The community on the reefs was dominated by the filamentous brown alga Ectocarpus sp., stretching as a dense floating layer across the tide pools, with $U$. pinnatifida and other species (Table 1) growing underneath and between the Ectocarpus filaments. Thalli of U. pinnatifida grew in clusters of one to seven individuals as epibionts (attached to living surfaces) of other species (basibionts), with 34 clusters in total, spread over a system of connected tide pools no deeper than $30 \mathrm{~cm}$ during low tide.

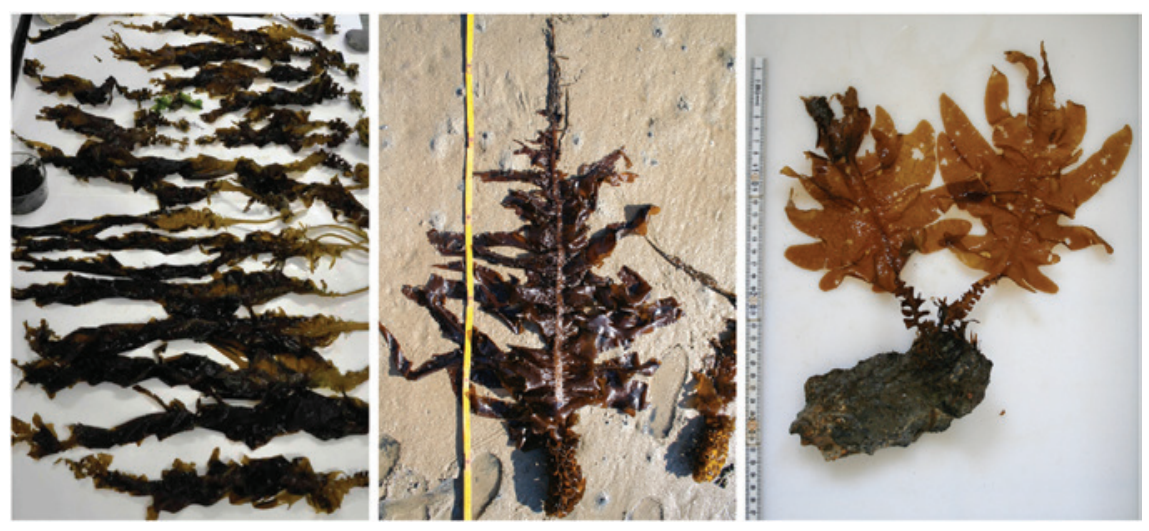

Figure 2: Undaria pinnatifida sporophytes collected at Sylt, Germany.

(Left) Specimens washed up in the intertidal between Rantum and Hörnum during low tide. (Middle) Large fertile sporophyte found floating in tide pools of the sampled oyster reef. (Right) Individuals collected growing on oysters in the tide pools. 
Table 1: Undaria pinnatifida associated flora and fauna identified at the northern oyster reef $\left(54^{\circ} 47^{\prime} 44.4^{\prime \prime} \mathrm{N} 8^{\circ} 18^{\prime} 24.7^{\prime \prime} \mathrm{E}\right)$, Sylt, Germany.

\begin{tabular}{|c|c|c|c|}
\hline \multicolumn{2}{|l|}{ Plantae } & \multicolumn{2}{|l|}{ Animalia } \\
\hline \multirow[t]{2}{*}{ Chlorophyta } & Ulva sp. (narrow) & Mollusca & Magallana gigas \\
\hline & Ulva sp. (wide) & & Mytilus edulis \\
\hline \multirow[t]{4}{*}{ Rhodophyta } & Gracilaria vermiculophylla & & Littorina littorea \\
\hline & Chondrus crispus & & Crepidula fornicata \\
\hline & Dasya baillouviana & Crustacea & Carcinus maenas \\
\hline & Ceramium rubrum & & Semibalanus balanoides \\
\hline \multirow[t]{5}{*}{ Ochrophyta } & Ectocarpus sp. & Polychaeta & Lanice conchilega \\
\hline & Sargassum muticum & & Arenicola marina \\
\hline & Fucus vesiculosus & Bryozoa & Electra pilosa \\
\hline & Chorda filum & Echinodermata & Asterias rubens \\
\hline & Dictyota dichotoma & Cnidaria & Metridium senile \\
\hline
\end{tabular}

The majority of the thalli (91\%) were attached to Pacific oysters Magallana [Crassostrea] gigas, while 7.7\% were growing on Mytilus edulis and a single thallus grew on a sponge.

Nearly all of the sporophytes were damaged at the tip of the blade, likely due to wave exposure and the onset of senescence due to high temperature or age.

The mean actual length \pm standard deviation (SD) of the 91 attached sporophytes was $21.5 \pm 8.5 \mathrm{~cm}$, while the mean full length \pm SD was estimated to be $30.6 \pm 10.7 \mathrm{~cm}$ (Figure 3). The longest thallus was estimated to be about $70 \mathrm{~cm}$ before damage.

Additionally, 41 floating Undaria pinnatifida sporophytes were photographed in January 2017 (Figure 2) of which 13 could be reliably measured from the photos and 36 and 16 were measured in late March and June 2017, respectively. Of these, the mean actual length

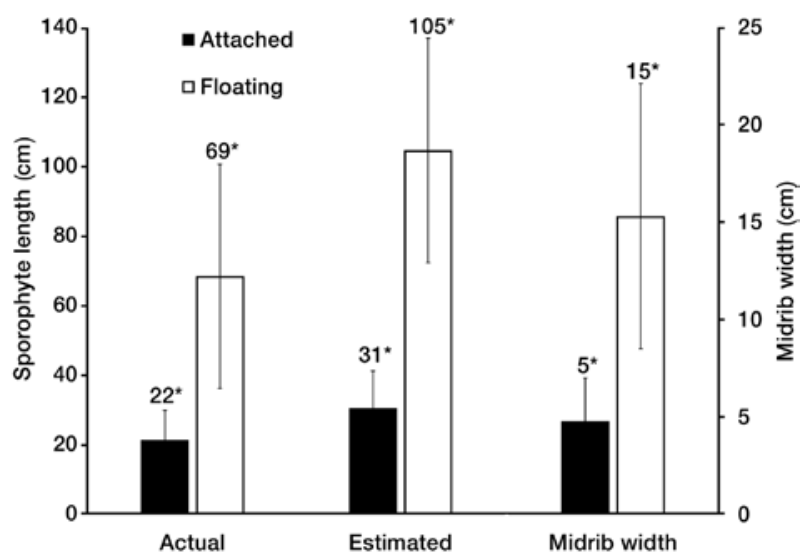

Figure 3: Undaria pinnatifida: actual and estimated length (left) and midrib width (right) of 91 attached (black) and 73 floating (white) sporophytes.

Values above bars are means; bars indicate standard deviations. Significant differences $(p \leq 0.05)$ between the attached and floating specimens of each parameter are indicated by asterisks. was $68.5 \pm 32.2 \mathrm{~cm}$ and the mean estimated length $104.7 \pm 32.3 \mathrm{~cm}$ (Figure 3) with the longest sporophyte estimated to be $149 \mathrm{~cm}$ before damage. The significantly longer thalli and wider midribs compared to those found in attached thalli suggest another source habitat. Within the oyster reefs current speed is reduced with stagnant water in low tide pools. Peteiro and Freire (2011) found that $U$. pinnatifida growing at a site moderately exposed to water currents had significantly larger sporophytes, compared to a sheltered site. The average total length reported for a moderately exposed site in Northwest Spain was $122 \mathrm{~cm}$, compared to $86 \mathrm{~cm}$ at a sheltered site (Peteiro and Freire 2011). This suggests that our floating sporophytes originate from tidal channels with swift currents rather than from another oyster reef with low tide pools.

Floating sporophytes were collected over a period of more than 6 months, and they always had sporophylls, suggesting that different states of the population and several generations were documented. This agrees with the observation that Undaria pinnatifida sporophytes occurred year round with several recruitment pulses where maximum sea surface temperatures are $\leq 19.4^{\circ} \mathrm{C}$ (James et al. 2015 and references therein).

We identified $69(76 \%)$ of the attached individuals that had formed sporophylls. Out of 27 tested for spore release, $85 \%$ had released spores after $4 \mathrm{~h}$. After $24 \mathrm{~h}, 89 \%$ had released spores of which $82 \%$ had formed germination tubes. However, it has been noted by Forrest et al. (2000) that germination into gametophytes could occur up to 14 days after the release of spores. The high spore release and germination rates, together with the successful growth of sporophytes from this material, provide strong evidence that reproduction and potential range expansion are possible in the Undaria pinnatifida population from Sylt.

From field observations, it was concluded that Undaria pinnatifida arrived at the oyster reefs by natural 
dispersal through floating mature thalli. The fact that attached individuals were found only on the landward side of the reef and in tide pools, suggests that floating individuals were trapped in these pools during low tide. Spores released there are likely to remain in these pools, allowing them to settle in the observed patches. Pang and Shan (2008) argued that water velocity was the most important factor for spore attachment. Undaria pinnatifida spores were able to attach best under low water velocities, but attached permanently to the substratum if allowed to settle for an hour before exposure to higher velocities (Pang and Shan 2008). The tide pools sampled near Sylt provide the necessary time for settlement during low tide.

Undaria pinnatifida was not found in any harbour on Sylt, nor on the neighbouring island of Föhr or in any other oyster reef around Sylt that was surveyed. Additionally, thalli were only washed up in a rather narrow beach area on Sylt. Therefore, it is likely that only one main population exists in subtidal waters and that this is the source of the large floating sporophytes. Further surveys in a wider area will be conducted to locate this population.

Compared to other invasions in Europe and worldwide, the presence exclusively on natural substratum is rather unusual, as Undaria pinnatifida has shown a preference for artificial substrates (Minchin and Nunn 2014). In cases where it was found in natural habitats, it was usually after a population had been observed first on man-made structures (i.e. James and Shears 2016). Prior to the findings on Sylt, several other German marinas closer to the known Dutch populations (Emden, Bensersiel, Wilhelmshaven, Cuxhaven, Brunsbüttel, Büsum, Langeoog, Borkum, Helgoland) had been screened but U. pinnatifida was found in none of them (Schiller/Lackschewitz, own observations). During assessments of nonnative species in the Dutch Wadden Sea by Gittenberger et al. (2015), no populations were found east of Terschelling, even though areas of hard substrate were sampled all the way to the German border.

Forrest et al. (2000) illustrated that the natural spread of Undaria pinnatifida is generally restricted to approximately $100 \mathrm{~m}$ per year even when considering floating sporophylls. The direct distance between Terschelling and Sylt is $240 \mathrm{~km}$ and along the coast it is $300 \mathrm{~km}$ (Figure 1B), so that it is unlikely that this present record of range expansion is due to natural dispersal. Coastal shipping has been shown to play a significant role in the dispersal of U. pinnatifida (Hay 1990), and during summer many recreational boats visit Sylt. Extensive mussel cultures on ropes and the sea floor are located in the proximity of the reported $U$. pinnatifida localities. These relied on seed mussel translocations from other North Sea regions in the past and farming vessels still frequently transfer between Sylt and other farms.

\section{Conclusion}

Our study documents the successful establishment of a Undaria pinnatifida population much further north on the European continental coast than previously known. Laboratory experiments proved that the majority of the sporophytes had reached maturity and released spores that were capable of germinating and forming a new generation of sporophytes in vitro. Thus, we conclude that a self-sustaining population now exists in the Northern Wadden Sea and may disperse northwards from there. By continuous monitoring, ecophysiological characterization, interaction studies, genetic analyses and species distribution modelling, we will aim to understand and predict its further spread.

Acknowledgements: The authors are grateful to the funding provided by the Sino-German Center for Research Promotion (CDZ 1080) and the Deutsche Forschungsgemeinschaft, Funder ID: 10.13039/501100001659 (Bi 772/14-1). We also acknowledge G. Wicht for kindly sharing his observations on attached U. pinnatifida with us and sincerely thank the reviewers for their constructive input.

\section{References}

Bollen, M., C.N. Battershill, C.A. Pilditch and K. Bischof. 2017. Desiccation tolerance of different life stages of the invasive marine kelp Undaria pinnatifida: potential for overland transport as invasion vector. J. Exp. Mar. Biol. Ecol. 496: 1-8.

Buschbaum, C., D. Lackschewitz and K. Reise. 2012. Nonnative macrobenthos in the Wadden Sea ecosystem. Ocean Coast Manage 68: 89-101.

Casas, G., R. Scrosati and M. Luz Piriz. 2004. The invasive kelp Undaria pinnatifida (Phaeophyceae, Laminariales) reduces native seaweed diversity in Nuevo Gulf (Patagonia, Argentina). Biol. Invasions 6: 411-416.

Castric-Fey, A., C. Beaupoil, J. Bouchain, E. Pradier and M.T. L'Hardyhalos. 1999. The introduced alga Undaria pinnatifida (Laminariales, Alariaceae) in the rocky shore ecosystem of the St Malo area: growth rate and longevity of the sporophyte. Bot. Mar. 42: 83-96.

Dean, P.R. and C.L. Hurd. 2007. Seasonal growth, erosion rates, and nitrogen and photosynthetic ecophysiology of Undaria pinnatifida (Heterokontophyta) in southern New Zealand. J. Phycol. 43: 1138-1148.

Floc'h, J.Y., R. Pajot and I. Wallentinus. 1991. The Japanese brown alga Undaria pinnatifida on the coast of France and its possible 
establishment in European waters. ICES J. Mar. Sci. 47: 379-390.

Forrest, B.M., S.N. Brown, M.D. Taylor, C.L. Hurd and C.H. Hay. 2000. The role of natural dispersal mechanisms in the spread of Undaria pinnatifida (Laminariales, Phaeophyceae). Phycologia 39: 547-553.

Gittenberger, A., M. Rensing, R. Dekker, P. Niemantverdriet, N. Schrieken and H. Stegenga. 2015. Native and non-native species of the dutch wadden sea in 2014. GiMaRIS, Leiden. 2015_08: 35.

Hay, C.H. 1990. The dispersal of sporophytes of Undaria pinnatifida by coastal shipping in New Zealand, and implications for further dispersal of Undaria in France. Br. Phycol. J. 25: 301-313.

Hay, C.H. and P.A. Luckens. 1987. The Asian kelp Undaria pinnatifida (Phaeophyta: Laminariales) found in a New Zealand harbour. New Zeal. J. Bot. 25: 329-332.

Hay, C.H. and E. Villouta. 1993. Seasonality of the Adventive Asian Kelp Undaria pinnatifida in New Zealand. Bot. Mar. 36: 461-476.

Irigoyen, A.J., G. Trobbiani, M.P. Sgarlatta and M.P. Raffo. 2011. Effects of the alien algae Undaria pinnatifida (Phaeophyceae, Laminariales) on the diversity and abundance of benthic macrofauna in Golfo Nuevo (Patagonia, Argentina): potential implications for local food webs. Biol. Invasions 13: 1521-1532.

James, K. and N.T. Shears. 2016. Proliferation of the invasive kelp Undaria pinnatifida at aquaculture sites promotes spread to coastal reefs. Mar. Biol. 163: 34.

James, K., J. Kibele and N.T. Shears. 2015. Using satellite-derived sea surface temperature to predict the potential global range and phenology of the invasive kelp Undaria pinnatifida. Biol. Invasions 17: 3393-3408.

Lowe, S., M. Browne, S. Boudjelas and M. De Poorter. 2000. 100 of the world's worst invasive alien species: a selection from the global invasive species database. The Invasive Species Specialist Group (ISSG) of the Species Survival Commission (SSC) of the World Conservation Union (IUCN), Auckland, New Zealand.

Minchin, D. and J. Nunn. 2014. The invasive brown alga Undaria pinnatifida (Harvey) Suringar, 1873 (Laminariales: Alariaceae), spreads northwards in Europe. Biolnvasions Rec. 3: 57-63.

Minchin, D., J. Nunn, J. Murphy, H. Edwards and A. Downie. 2017. Monitoring temporal changes in the early phase of an invasion: Undaria pinnatifida (Harvey) Suringar using the abundance and distribution range method. Manag. Biol. Invasions 8: 53-60.

Morelissen, B., B.D. Dudley, S.W. Geange and N.E. Phillips. 2013. Gametophyte reproduction and development of Undaria pinnatifida under varied nutrient and irradiance conditions. J. Exp. Mar. Biol. Ecol. 448: 197-206.

Nisizawa, K., H. Noda, R. Kikuchi and T. Watanabe. 1987. The main seaweed foods in Japan. Dev. Hydrobiol. 41: 5-29.

Pang, S. and T. Shan. 2008. Zoospores of Undaria pinnatifida: their efficiency to attach under different water velocities and conjugation behavior during attachment. Acta Oceanol. Sin. 27: 1-8.

Peteiro, C. and Ó. Freire. 2011. Effect of water motion on the cultivation of the commercial seaweed Undaria pinnatifida in a coastal bay of Galicia, Northwest Spain. Aquaculture. 314: 269-276.

$\mathrm{R}$ Core Team. 2015. $R$ : a language and environment for statistical computing. R Foundation for Statistical Computing, Vienna, Austria.

Redmond, S., L. Green, C. Yarish, J. Kim and C. Neefus. 2014. New England Seaweed Culture Handbook. Seaweed Cultivation. Paper 1.

Schneider, C., W. Rasband and K. Eliceiri. 2012. NIH Image to ImageJ: 25 years of image analysis. Nat. Methods 9: 671-675.
Shan, T.F. and S.J. Pang. 2009. Assessing genetic identity of sporophytic offspring of the brown alga Undaria pinnatifida derived from mono-crossing of gametophyte clones by use of amplified fragment length polymorphism and microsatellite markers. Phycol. Res. 57: 36-44.

Shan, T.F., S.J. Pang and S.Q. Gao. 2013. Novel means for variety breeding and sporeling production in the brown seaweed Undaria pinnatifida (Phaeophyceae): crossing female gametophytes from parthenosporophytes with male gametophyte clones. Phycol. Res. 61: 154-161.

Shan, T.F., S.J. Pang, J. Li and S.Q. Gao. 2016. Breeding of an elite cultivar Haibao no. 1 of Undaria pinnatifida (Phaeophyceae) through gametophyte clone crossing and consecutive selection. J. Appl. Phycol. 28: 2419-2426.

Skriptsova, A., V. Khomenko and I. Vladimir Isakov. 2004. Seasonal changes in growth rate, morphology and alginate content in Undaria pinnatifida at the northern limit in the Sea of Japan (Russia). J. Appl. Phycol. 16: 17-21.

Wotton, D.M., C. O’Brien, M.D. Stuart and D.J. Fergus. 2004. Eradication success down under: heat treatment of a sunken trawler to kill the invasive seaweed Undaria pinnatifida. Mar. Pollut. Bull. 49: 844-849.

Yamanaka, R. and K. Akiyama. 1993. Cultivation and utilization of Undaria pinnatifida (wakame) as food. J. Appl. Phycol. 5: 249-253.

\section{Bionotes}

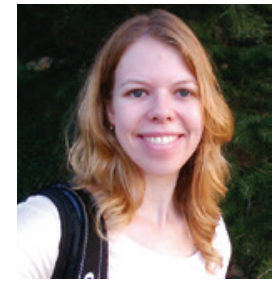

Jessica Schiller

Bremen Marine Ecology (BreMarE), Marine Botany, University of Bremen, Leobener Str. 3, 28359 Bremen, Germany, j.schiller@uni-bremen.de

Jessica Schiller completed her Bachelor's degree in Biology and her Master's degree in Marine Biology at the University of Bremen. Since 2016, she is a doctoral student at the department of Marine Botany at the same university, focusing on the spread and physiology of the invasive kelp Undaria pinnatifida in Europe and its cultivation in China in a cooperation with the IOCAS Qingdao, China.

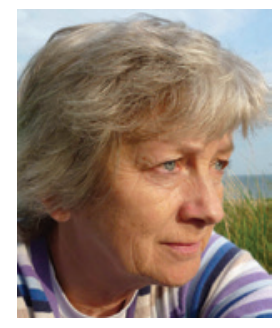

\section{Dagmar Lackschewitz}

Alfred Wegener Institute, Helmholtz Centre for Polar and Marine Research, Wadden Sea Station Sylt, Hafenstr. 43, 25992 List, Germany

Dagmar Lackschewitz studied Biology at the universities of Bremen and Göttingen. After her PhD at a Max-Planck-Institute in Göttingen she worked at Yale University (New Haven) and the University of South Florida (St. Petersburg). In 1992, she was employed at the Wadden Sea Station Sylt, Alfred Wegener Institute. Since 2009, her main research focus is on introduced species in coastal waters. 


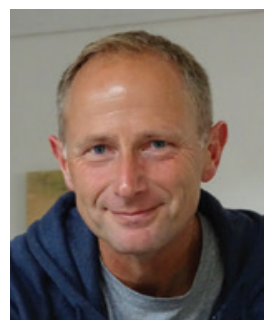

Christian Buschbaum

Alfred Wegener Institute, Helmholtz Centre for Polar and Marine Research, Wadden Sea Station Sylt, Hafenstr. 43, 25992 List, Germany

Christian Buschbaum is a marine ecologist at the Alfred Wegener Institute, Helmholtz Centre for Polar and Marine Research. One of his main research interests are species interactions in biotic structures such as kelp forests. Currently, he mainly works on the effects of introduced organisms on native communities at sedimentary coastal systems and he conducts large-scale ecological comparisons from temperate to Arctic regions.

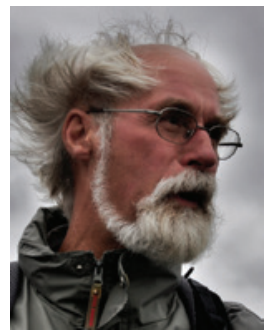

\section{Karsten Reise}

Alfred Wegener Institute, Helmholtz Centre for Polar and Marine Research, Wadden Sea Station Sylt, Hafenstr. 43, 25992 List, Germany

Karsten Reise, professor emeritus at Kiel University, Germany and scientist at Alfred Wegener Institute, Helmholtz Centre for Polar and Marine Research, Wadden Sea Station Sylt (AWI), PhD at Göttingen University in 1976, professorships at Göttingen, Hamburg and Kiel University in Zoology, Biological Oceanography and Coastal Ecology, respectively. Special interests in tidal flat ecology, sea level rise and introduced alien species.

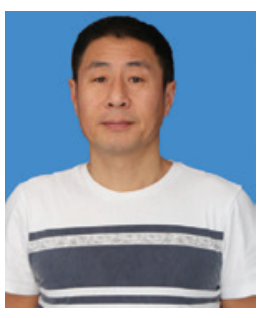

\section{Shaojun Pang}

Institute of Oceanology, Chinese Academy of Sciences, Qingdao 266071, P.R. China

Shaojun Pang is now directing the Seaweed Stock Culture Centre at Institute of Oceanology, Chinese Academy of Sciences. His main research field is to collect and preserve important stock resources of kelp species and apply them in the breeding and cultivation industry. Currently, he mainly focuses on breeding high quality cultivars of Saccharina japonica and Undaria pinnatifida in order to accelerate the development of their farming industry in China.

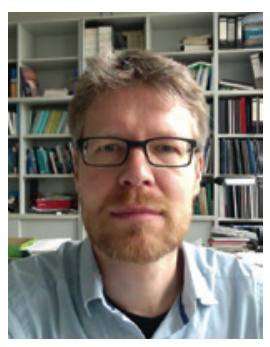

Kai Bischof

Bremen Marine Ecology (BreMarE), Marine Botany, University of Bremen, Leobener Str. 3, 28359 Bremen, Germany

Kai Bischof heads the Department of Marine Botany at the University of Bremen and has a strong research focus on the ecophysiology of seaweeds, more specifically in the field of photo- and stress physiology of kelps, adaptive mechanisms, and the consequences for interspecific competition and range expansion. He continues to be involved in a multitude of research projects in both the Arctic and Antarctic, and maintains international co-operations with partners in Chile, Norway, China and New Zealand. 